\title{
HUBUNGAN PEMBERIAN PREMI PANEN KELAPA SAWIT DENGAN MOTIVASI KERJA KARYAWAN PANEN DI PT. NIAGAMAS GEMILANG KABUPATEN KUTAI KARTANEGARA PROVINSI KALIMANTAN TIMUR
}

\section{CORRELATION OF HARVEST PREMIUM PROVISION WITH EMPLOYEE'S WORK MOTIVATION IN PT. NIAGAMAS GEMILANG}

\author{
Misnati Prihartini, Fadli Mulyadi, Rossy Mirasari \\ Politeknik Pertanian Negeri Samarinda \\ Misna0807@gmail.com
}

\begin{abstract}
Harvesting is important thing for oil palm company, because of that the company needs skilled harvesting employee. In order to achieve the company's goal thus the company needs to encourage employee by providing harvest premium to escalate employee's motivation. Therefore, this study aims to look for the correlation of giving harvest premium toward employee's work motivation.

This study used quantitative description method with questioner and interview as method ofcollecting data. The subject of this study was 30 married harvesting employees. Based on the calculation result, researcher obtained the value of coefficient of correlation by 0,334 which mean the value of correlation (r) was between 0,20-0,399 which mean there was a weak correlation between premium variable $(X)$ and motivation $(Y)$. And the level of significance by 0,074 which washigher than the significance level of 0,05 thus could be concluded that provision of the harvest premium had a weak correlation toward employee work motivation and harvest premium had no significant effect on work motivation allegedly because the lack of fresh fruit bunches that ready to harvest in the field, field conditions and harvester productivity.
\end{abstract}

Keywords: premium and work motivation.

\section{PENDAHULUAN}

Perkebunan kelapa sawit merupakan salah satu komoditi yang cukup populer saat ini untuk dikembangkan. Kelapa sawit merupakan komoditi perkebunan yang sedang menjadi unggulan indonesia. Karena memiliki nilai ekonomis yang tinggi dan merupakan penyumbang devisa bagi negara dibandingkan komoditi perkebunan lainya. Indonesia merupakan salah satu produsen utama minyak kelapa sawit dengan luas areal mecapai 34,18\% dari luas areal kelapa sawit dunia. Dengan ratarata produksi mencapai 75,54 juta ton tandan buah segar (TBS) pada tahun 2004 sampai 2008 (Fauzi, 2012).

Di Kalimantan Timur hingga tahun 2017 luas areal kelapa sawit mencapai 1.192 .342 ha yang terdiri dari 284.523 ha sebagai tanaman plasma / rakyat, 14.402 ha milik BUMN sebagaiinti dan 893.417 ha milik perkebunan besar swasta. Areal I perkebunan kelapa sawit yang cukup luas saat ini terpusat di Kabupaten Kutai Timur, Kutai Kartanegara dan Paser. Sedangkan beberapa Kabupaten dan Kotalainnya masih dalam luasan terbatas. Dengan semakin meluasnya sektor perkebunan pada komoditi kelapa sawit tentu memberikan manfaat yang baik pada masyarakat khususnya dalam peningkatan ekonomi dengan semakinluas areal perkebunan maka semakin banyak tenaga kerja yang dibutuhan, jumlah tenaga kerja yang terserap di Kalimatan Timur sebesar 234.063 orang berdasarkan rekapitulasi luas areal, produksi dan tenaga kerja menurut Kabupaten / Kota pada tahun 2017 (Anonim, 2018).

Pardamean (2017) menyatakan bahwa, panen merupakan salah satu kegiatan yang sangat penting bagi perusahaan kelapa sawit yang sudah menghasilkan. Dengan melakukan pengelolan tamaman yang baik dan potensi produksi yang baik juga hal ini tidak akan berguna jika tidak melakukan secara optimal pada saat melakukan pemanenan TBS. Oleh 
karena itu perusahaan perkebunan membutuhkan karyawan panen yang trampil di bidangnya. Sunarko (2014) menyatakanbahwa, karyawan panen adalah orang yang bertugas memanen TBS, mengangkut hasil panen, dan mengutip brondolan. Untuk mendapatkan hasil panen yang baik dalam kuantitas maupun kualitas perlu adanya motivasi untuk karyawan panen. Hasibuan (2008) menyatakan bahwa, motivasi dapat menciptakan kegairahan kerja seseorang agar mau bekerja sama dan bekerja efektif. Dengan adanya motivasi akan mendorong karyawan kebun untuk bekerja lebih keras lagi danberupaya untuk mencapai tujuan perusahaan. Salah satu cara memberikan motivasi kepada karyawan agar bekerja lebih keras lagi adalah dengan memberikan premi kepada karyawanyang bekerja melebihi batas atau ketentuan dari perusahaan. Tujuan pemberian premi adalah untuk meningkatkan pendapatankaryawan dan memotivasi pemanen agar tidak ada buah matang yang tertinggal dilapangan(Perdamean, 2017).

Hasil penelitian Fitriani (2015), menyatakan bahwa terdapat hubungan yang signifikan antara insentif terhadap motivasi kerja karyawan. Hal tersebu bertolak belakang dengan penelitian Pratama dkk (2015), yang menyatakan bahwa insentif materil tidak berpengaruh secara signifikan terhadap motivasi kerja karyawan.Berdasarkan hal-hal tersebut maka penulis melakukan penelitian mengenai hubungan premi dengan motivasi karyawan panen. Maka rumusan masalah dalam penelitian ini adalah sejauh mana Hubungan pemberian premi panen terhadap motivasi kerja karyawan panen.

Penelitian ini hanya membahas tentang seberapa besar hubungan pemberian premi panen terhadap motivasi kerja karyawan panen yang berstatus sudah menikah alasan pengambilan responden yang hanya berstatus sudah menikah karena perbedaan kebutuhan karyawan yang sudah memiliki keluarga kebutuhan pengeluaranya lebih banyak berbeda dengan yang belum menikahkebutuhan pengeluarannya cenderung lebih sedikit.Yuhansyah (2018) menyatakan bahwa motivasi merupakan suatu proses yang tidak disadari, jadi dalam setiap individu kebutuhan untuk memotivasi berbeda dari waktu ke waktu kuncinya adalah kebutuhan mana yang paling dominan pada saat itu. Deliarnov (2006) menyatakan bahwa, semakin banyak jumlah anggota keluarga atau tanggungan keluarga maka semakin banyak pula jenis kebutuhan keluarga yang bersangkutan.

Tujuan yang ingin dicapai dari penelitianini adalah sebagai berikut ini :

1. Mengidentifikasikan tentang premi panen

2. Mengindentifikasi motivasi kerja karyawan panen

3. Mengetahui seberapa besar korelasi pemberian premi dengan motivasi kerja karyawan

\section{METODE PENELITIAN}

\section{Alat Dan Bahan}

Alat yang digunakan adalah alat tulis, handphone, laptop, aplikasi Microssoft word, excel, dan SSPS dan buku-buku sebagi refrensi. Bahan yang digunakan adalah kuesioner dan wawancara.

\section{Metode Pengambilan data}

Pengumpulan data yang dilakukan oleh penulis meliputi pengambilan data primer maupun data sekunder. Data primer adalah data yang diproleh secara langsung melalui pengamatan secara langsung yang dilakukan penulis dilapangan yang berkaitan dengan masalah yang diteliti yaitu dengan melalui instrument wawancara dan kuisioner.

\section{Sampel}

Sampel adalah sebagian atau wakil populasi yang diteliti. Pada penelitian ini teknik pemilihan sampel sebagai responden yang digunakan adalah sampling/ sampel jenuh, yaitu seluruh karyawan panen yang sudah menikah sebanyak 30 orang responden.

Alasan pengambilan respondenyang hanya berstatus sudah menikah karena perbedaan kebutuhan karyawan yang sudah memiliki keluarga kebutuhan pengeluaranya lebih banyak berbeda dengan yang belum menikah kebutuhan pengeluarannya cenderung lebih sedikit.

\section{Analisa Data}

Metode analisis data yang digunakan dalam penelitian ini adalah dengan menggunakan statistik korelasi pearson product moment dengan alat uji statistik SPSS. Penelitian ini memiliki dua variabel yaituX dan $\mathrm{Y}$. Variabel 
$\mathrm{X}$ adalah Premi panen dan Variabel $\mathrm{Y}$ adalah Motivasi.

\section{Korelasi Product Moment}

Koefisien korelasi yaitu melakukan penelitian dengan menghubungkan antara variabel $X$ dan $Y$ untuk mengetahui derajat atau kekuatan dan arah hubungan antar dua variabel (Sugiono, 2013).

Nilai korelasi $(r)=(-1 \leq 0 \leq 1)$. Untuk kekuatan koefisien korelasi berada di antara -1 sampai 1, dan arah di tentukan berdasarkan positif $(+)$ dan negatif (-). Yang artinya apabila $r$ $=-1$ korelasi negatif sempurna, artinyaterjadinya hubungan yang bertolak belakang antara variabel $X$ dan $Y$. jika variabel $X$ naik maka variabel $Y$ turun. Dan $r=1$ korelasi sempurna, yang berarti terjadi hubungan yang searah antara variabel $X$ dan $Y$. Jika variabel Xnaik maka variabel $Y$ juga naik dengan rumus :

$$
\begin{aligned}
r_{x y}= & \frac{N \sum X Y-\left(\sum X\right)\left(\sum Y\right)}{} \\
& \sqrt{ }\left[\left(n \sum x^{2}-\left(\sum X\right)^{2}\left(n \sum y^{2}-\left(\sum y\right)^{2}\right)\right]\right.
\end{aligned}
$$

\section{Keterangan :}

$$
\begin{array}{ll}
\mathrm{r} & =\text { Besarnya korelasi antara } \mathrm{X} \text { dan } \mathrm{Y} \\
\mathrm{n} & =\text { Jumlah Sampel (Responden) } \\
\mathrm{X} & =\text { Variabel } \mathrm{X} \text { (Premi) } \\
\mathrm{y} & =\text { Variabel } \mathrm{Y} \text { (Motivasi) }
\end{array}
$$

Tabel 1.Tingkat Korelasi dan Kekuatan Hubungan

\begin{tabular}{cc}
\hline Nilai Korelasi $(r)$ & Tingkat hubungan \\
\hline $0,00-0,199$ & Sangat Lemah \\
$0,20-0,399$ & Lemah \\
$0,40-0,599$ & Cukup \\
$0,60-0,799$ & Kuat \\
$0,80-0,100$ & Sangat Kuat \\
\hline
\end{tabular}

\section{HASIL DAN PEMBAHASAN}

\section{Karakteristik RespondenUsia}

Tabel 2. Distribusi dan Frekuensi Karakteristik

Tingkat Usia Tenaga Kerja Panen

\begin{tabular}{ccc}
\hline Usia & Frekuensi & Presentase \\
\hline $21-29$ & 0 & $0 \%$ \\
$30-38$ & 11 & $37 \%$ \\
$39-45$ & 15 & $50 \%$ \\
$>45$ & 4 & $13 \%$ \\
\hline Jumlah & 30 & $100 \%$ \\
\hline
\end{tabular}

Pada tabel 2 di atas dapat dilhat mayoritas responden berusia 39-45 tahun. Hal ini diduga karena dengan mempunyai bannyak pengalaman akan menambah pengetahuan karyawan walaupun secara fisik tidak semaksimal seperti pada saat berusia 20 tahunan. . Pada umurnya, tenaga kerja yang berumur tua mempunyai tenaga fisik yang lemah dan terbatas sebaliknya tenaga kerja berumur muda mempunyai kemampuan fisik yang kuat (Mahendra, 2014).

\section{Jenis Kelamin}

Tabel 3. Distribusi dan Frekuensi Karakteristik Responden Berdasarkan Jenis Kelamin

\begin{tabular}{ccc}
\hline Jenis Kelamin & Frekuensi & Presentase \\
\hline Laki - laki & 30 & $100 \%$ \\
Perempuan & 0 & $0 \%$ \\
\hline Jumlah & 30 & $100 \%$ \\
\hline
\end{tabular}

Pada tabel 3 di atas dapat dilihatmayoritas responden adalah laki-laki. Hal ini diduga dalam pelaksanaan tugas dan fungsi perusahaan membutuhkan pemanen yang memiliki kekuatan tangan yang kuat dan teknik dalam memegang alat panen tersebut sehinggadapat tercapai produktifitas dan kinerja yang tinggi. Hal ini didukung oleh Sarwono (2007) yang menyatakan bahwa, dengan bekerja mencari nafkah masih didominasi laki-laki sebagai kepala keluarga untuk pekerjaan rumah didominasi perempuan.

\section{Pendidikan}

Tabel 4. Distribusi dan Frekuensi Karakteristik Responden Berdasarkan Pendidikan.

\begin{tabular}{ccc}
\hline Pendidikan & Frekuensi & Presentase \\
\hline SD/ Sederajat & 8 & $27 \%$ \\
SMP/ Sederajat & 10 & $33 \%$ \\
SMA/ Sederajat & 12 & $40 \%$ \\
Perguruan tinggi & 0 & $0 \%$ \\
\hline Jumlah & 30 & $100 \%$ \\
\hline
\end{tabular}

Pendidikan responden didominasi oleh SMA/ Sederajat atau tidak ada pendidikan lebih dari SMA hal ini diduga latar belakang pendidikan tidak terlalu dibutuhkan karena yang lebih dibutuhkan adalah kinerja karyawan secara teknis bukan teoritis. 
Perdamean (2017) menyatakan bahwa, perusahaan membutuhkan karyawan panen yang trampil dengan kriteria penerimaan karyawan melalui seleksi keterampilan, motivasi, disiplin dan kesehatan yang baik.

\section{Masa Kerja}

Tabel 5. Distribusi dan Frekuensi Karakteristik Responden Berdasarkan Masa Kerja

\begin{tabular}{lcc}
\hline Masa kerja & Frekuensi & Presentase \\
\hline$<1$ tahun & 5 & $17 \%$ \\
1 tahun & 5 & $17 \%$ \\
2 tahun & 12 & $40 \%$ \\
$>3$ tahun & 8 & $26 \%$ \\
\hline Jumlah & 30 & $100 \%$ \\
\hline
\end{tabular}

Pada tabel 5 dapat dilihat bahwa mayoritas responden lama bekerja selama 2 tahun. Hal tersebut diduga masa kerja responden dapat menggambarkan kemampuan dan kesiapan dalam suatu bidang pekerjaan yang bisa menjadi salah satu pertimbangan dalam penerimaan tenaga kerja. Hal ini didukung Suparyadi (2015) menyatakan bahwa lamanya perjalanan karir seseorang dalam suatu organisasi maka pengalaman yang diperoleh semakin bertambah atau dengan katalain bahwa akan semakin banyak pengalaman seseorang karyawan apabila masa kerjasemakin banyak.

\section{Jumlah Tanggungan}

Tabel 6.Distribusi dan Frekuensi Karakteristik Responden Berdasarkan Jumlah Tanggungan

\begin{tabular}{ccc} 
Jumlah tanggungan & Frekuensi & Presentase \\
1 orang & 2 & $7 \%$ \\
2 orang & 11 & $37 \%$ \\
3 orang & 12 & $40 \%$ \\
>4 orang & 5 & $17 \%$ \\
\hline Jumlah & 30 & $100 \%$
\end{tabular}

Pada tabel 6. diatas dapat dilihat mayoritas responden memiliki jumlah tanggungan sebanyak 3 orang. sehingga diduga banyaknya tanggungan merupakan salah satu alasan mengapa responden meningkatkan kinerjanya dengan berusaha mendapatkan premi panen untuk meningkatkan penghasilan responden setiap bulannya. Semakin banyak banyak jumlah anggota keluarga atau tanggungan keluarga maka semakin banyak pula jenis kebutuhan keluarga yang bersangkutan
(Deliarnov, 2006).

\section{Uji Pearson Correlation}

\begin{tabular}{llrr} 
Tabel. 3 Hasil Uji Pearson Correlation \\
\hline \multicolumn{3}{c}{ Corelations } \\
PREMI & \multicolumn{1}{c}{ PREMI } & \multicolumn{1}{c}{ MOTIVASI } \\
& Pearson & 1 & 0.334 \\
& Correlations & & \\
& Sig. (2-tailed) & 30 & 0.071 \\
& N & 30 \\
& Pearson & 0.334 & 1 \\
& Correlations & & \\
MOTIVASI & Sig. (2-tailed) & 0.071 & \\
& $N$ & 30 & 30 \\
\hline
\end{tabular}

Koefisien korelasi sebesar 0,344 dengan $r_{\text {tabel }}$ diperoleh sebesar 0,361 sehingga dapat dilihat $r_{\text {hitung }}$ lebih kecil dari $r_{\text {tabel. }}$. Hal tersebut menunjukkan terdapat hubungan yang positif dan tidak signifikan antara pemberian premi panen terhadap motivasi kerja. Hal tersebut berarti jika premi panen meningkat maka motivasi kerja meningkat namun jika premi panen menurun tidak dapat diketahui apakah hubungan pemberian premi panen terhadap motivasi kerja naik atau menurun.

Premi panen adalah bayaran darimemanen TBS melebihi target yang diberikan oleh perusahaan. Pahan (2010) menyatakan bahwa, premi merupakan bayaran lebih yang diberikan oleh perusaahan kepada karyawan karena telah melakukan pekerjaan melebihi batas kerja yang ditentukan perusahaan. Premi panen sangat dekat dengan kinerja karyawan yang artinya semakin banyak karyawan memanen TBS maka semakin banyak pula insentif / premi yang di dapatkan.

Pada hasil penelitian diatas, menunjukkan bahwa terdapat hubungan yang positif antara pemberian premi panen terhadap motivasi kerja karyawan namun tidak mempengaruhi secara signifikan antara premi panen dan motivasi kerja. Kemungkinan hal ini dapat terjadi karena jumlah TBS yang di dapatkan rendah sehingga menurunkan pendapatan beruapa premi panen.

Hubungan lemah antara pemberian premi panen terhadap motivasi kerja diduga dapat disebabkan oleh beberapa hal seperti banyaknya TBS siap panen yang tersedia dilapangan serta kondisi lapangan. Kapasitas pemanen setiap hari tergantung pada produksi/ ha yang berhubungan dengan umur tanaman, topografi lahan, kerapatan pohon, insentif serta musim panen puncak dan musim panen rendah 
(Perdamean, 2014).

Selain itu berdasarkan pernyataan mandor, diduga pemanen yang tidak mencapai basis panen biasanya dipengaruhi oleh kemampuan panen menjaga rotasi panen sehingga pada musim panen rendah pemanen sulit mendapatkan TBS siap penen dan mengakibatkan kuantitas pemanen menurun, karena diperusahaan ini menggunakan ancak tetap pemanen hanya akan memanen panen di ancak yang telah ditentukan oleh perusahaan. Pahan (2010), yang paling menentukan dalam pekerjaan memanen TBS adalah rotasi panen guna mendapatkan hasil yang berkualitas tinggi dan kuantitas yang maksimal, selain itu hal ini juga berguna untuk mencegah biaya panen meningkat sementara output yang dihasilkan menurun.

Banyaknya TBS siap panen diduga merupakan salah satu motivasi pemanen untuk mendapatkan kuantitas panen semaksimal mungkin namun, tidak semua pemanen mampu memanen TBS melebihi basis setiap harinya. Kemampuan pemanen untuk melakukan panen dipengaruhi oleh kondisi fisik pemanen, biasanya pemanen sering dibantu oleh istri dan anak untuk mencapai terget (Perdamean, 2008).

Berdasarkan pemaparan diatas menunjukkan bahwa pemberian premi panen diduga bukan satu-satunya cara untuk memberikan motivasi kepada karyawan. Melainkan ada faktor lain yang diduga dapat mempengaruhi motivasi pemanen seperti bayaknya buah yang siap panen dilapangan dan produktivitas pemanen memanen TBS setiap harinya. Seperti pemanen yang memiliki motivasi dan produktifitas yang tinggi namun tidak dudukung oleh ketersediaan TBS siap panen dilapangan sehingga membuat pemanen memperoleh kuantitas yang tidak maksimal dan Sejalan dengan hal tersebut Dessler (2009) menyatakan bahwa, pemberian insentif/ premi hanya memberikan dorongan sesaat saja, yang meyebabkan semangat kerja meningkat karna diberikan insentif namun jika tidak diberikan insentif semangat kerja akan menurun.

Pendapat tersebut didukung oleh pernyataan Konsultan SDM Mercer, menemukan hanya 28\% dari 2.600 pekerja amerika yang menyatakan bahwa karyawan tersebut termotivasi atas rencana insentif (Desseler, 2007). Hal ini juga didukung oleh penelitian terdahulu Pratama dkk (2015) yang menyatakan bahwa insentif materil tidak berpengaruh secara signifikan terhadap motivasi kerja karyawan. Berdasarkan pemaparan diatas maka dapat diketahuiterdapat hubungan yang positif antara pemberian premi panen terhadap motivasi kerjakaryawan namum hubungannya tidak signifikankarena dipengaruhi oleh beberapa faktor seperti, kurangnya tersedia TBS dilapangan, kondisi lapangan, dan produktifitas pemanen.

\section{KESIMPULAN}

1. Berdasarkan hasil identifikasi responden mengenai tentang sistem premi panen mayoritas responden menjawab setuju tentang sistem dan standar pemberian premi panen dan skor tertinggi terletak pada pertayaan ke 6 tentang banyaknya buah siap panen merupakan acuan untuk mendapatkan premi panen. Hal ini didugakarena mayoritas responden sudah bekerja diperusahaan selama 2 tahun dengan presentase $40 \%$ sehingga responden sedikit banyaknya mengetahui tentang sistem pemberian premi panen. Yang dimana premi akan diberikan apabila karyawan melewati ketentuan yang telah ditentukan perusahaanmaka karyawan akan mendapatkan premi panen. Sehingga banyaknya buah yang siappanen merupakan salah satu acuan pemanen untuk mendapatkan premi panen.

2. Berdasarkan hasil indentifikasi mengenai motivasi kerja karyawan panen mayoritas responden setuju bahwa motivasi mereka bekerja keras melebihi ketentuan perusahaan karena ingin mendapatkanpremi berupa uang. Hal ini diduga karenamayoritas responden mempunyaitanggungan sebanyak 3 orang dengan presentase $40 \%$, sehingga dengan banyaknya jumlah tanggungan maka semakin banyak juga kebutuhan dan pengeluaran yang dikeluarkan untuk memnuhi kebutuhan hidup.

3. Pemberian premi panen mempunyai hubungan yang lemah namun, premi panen tidak memberikan hubungan yang signifikan terhadap motivasi kerja. 


\section{DAFTAR PUSTAKA}

Anonim.2017. Dinas Perkebunan Kalimantan Timur, (Online), (http://disbun.kaltimprov go.id/, diakses 5 November 2018).

Deliarnov. 2007. IImu Pengetahuan Sosial Ekonomi. Erlangga.

Dessler G. 2007. Manajemen Sumber Daya Manusia Edisi Ke Sepuluh Jilid Kedua.Jakarta : PT Indeks.

Fauzi Yan, Widyastuti YE, Satyawibawa I,dan Paeru RH. 2012. Kelapa Sawit Budi Daya Pemanfaatan Hasil dan Limbah Analisis Usaha dan Pemasaran. Depok: Penebar Swadaya

Fitriani dan Sihombing. 2015."Hubungan Premi Panen Terhadap Motivasi Kerja Karyawan: PT. Perkebunan Nusantara III (Persero) Medan". Bisnis Administrasi. Vol.04 No.01, 0816

Hasibuan Malayu. 2008. Organisasi Dan Motivasi. Jakarta:PT Bumi Aksara.

Pahan lyung. 2010. Panduan Lengkap Kelapa Sawit: Manajemen Agribisnis dari Hulu hingga Hilir.Jakarta: Penebar Swadaya.

Pardamean M. 2008. Panduan Lengkap Pengelolaan Kebun Dan Pabrik Kelapa Sawit. Jakarta Selatan: AgroMedia Pustaka.

.2014. Mengelola Kebun Dan Pabrik Kelapa Sawit Secara Profesional. Jakarta Timur: Penebar Swadaya

2017. Mengelola Kebun dan Pabrik Kelapa Sawit Secara Efektif dan Efisien. Jakarta Timur: Penebar Swadaya.

Pratama M. Rahmaditya, Al Musadieq Moch dan NP Maria Goretti Wi Endang. 2015.

Pengaruh Insentif Terhadap Motivasi Kerja Karyawann Atria Hotel and Conference Malang. Jurnal Administrasi Bisnis Universitas Brawijaya.

Sarwono, P. 2007. Ilmu Bedah Kebidanan. Bina Pustaka Banten.

Sunarko. 2014. Budi Daya Kelapa Sawit di Berbagai Jenis Lahan. Jakarta
Selatan: AgroMedia.

Suparyadi H. 2015. Manajemen Sumber Daya Manusia, Yogyakarta: CV ANDI OFFSET

Yuhansyah Iskandar. 2018. Pengaruh Motivasi \& Ketidakamanan Kerja Terhadap Penilaian Kerja yang Berdampak Kepada Kepuasan Kerja. Surabaya: MediaSahabat Cendekia 